\title{
The mathematics teachers' understanding of learning process based on 2013 curriculum 2017 revision
}

\author{
Ikhsan Abdul Latif, Riyadi, Dewi Retno Sari Saputro \\ Graduate Program of Mathematics Education, Sebelas Maret University, Indonesia
}

\begin{tabular}{l}
\hline \hline Article Info \\
\hline Article history: \\
Received May 07, 2018 \\
Revised Aug 31, 2018 \\
Accepted Jan 08, 2019 \\
\hline Keywords: \\
2013 Curriculum \\
2017 Revision \\
Civil servant \\
Honorary \\
Mathematics teacher
\end{tabular}

\begin{abstract}
This study is a qualitative research with case study strategy that aims to describe the understanding of Mathematics teacher about the learning process based on 2013 Curriculum (K13) 2017 Revision. The subjects of this study are a Mathematics teacher who has status as a Civil Servant and Honorary at SMAN 1 Wuryantoro, Wonogiri Regency. The result of this study is generally, the understanding of the two Mathematics teachers about the learning process based on K13 2017 Revision have been appropriate to the guidelines K13 2017 Revision by the Ministry of Education and Culture of Indonesia. However, the Honorary teacher's understanding of the learning process has not been appropriate to the Assessment Guidelines by Educators and the High School Education.
\end{abstract}

Copyright $\odot 2019$ Institute of Advanced Engineering and Science. All rights reserved.

\section{Corresponding Author:}

Ikhsan Abdul Latif, Graduate Program of Mathematics Education,

Sebelas Maret University,

36A Ir. Sutami Street, Jebres, Surakarta, Indonesia.

Email: al_ikhsan2@student.uns.ac.id

\section{INTRODUCTION}

The curriculum is central to all the processes and experiences occurring in school settings [1]. The curriculum is a guide in organizing the plans, objectives, lesson materials, and methods used in education. The applicable curriculum should be developed in accordance with the times to fit the present and future conditions. The curriculum should always be updated in line with the changes to keep it relevant to the changing society. Curriculum development should take into account various aspects such as child development, the development of science, the development society's needs and employment and so on [2].

The 21 st century forces people to develop in harmony with advances in information and technology. To be able to compete locally and internationally in the 21 st Century, humans are required to have $21 \mathrm{st}$ Century skills. The 21 st Century skills want the current knowledge oriented learning paradigm project, problems, investigation, discovery, and creation [3]. Based on this, the Indonesian government through the Ministry of Education and Culture develops education for human beings in Indonesia can compete in the $21 \mathrm{st}$ Century. Education in the 21 st Century is an education that integrates knowledge, high-level thinking skills, attitudes, and mastery of information technology.

The 2013 curriculum (K13) is one of the tools to create human developing in Indonesia that is in accordance with demands, needs, and conditions related to social life. The K13 encourages students to be active and find learning by themselves through observing, discussing, experimenting, and collaborating activities. Learning in K13 is carried out in three stages; these are the introduction, the contents, and the evaluation. The assessment in K13 prioritizes assessment as learning and assessment for learning compared to assessment of learning so that students and teachers can know the weakness and the advantages of learning that has been done. By knowing the weakness of learning that has been done, learning outcomes will increase because students are given reinforcement on things that have been found. The K13 has been developed by the 
Indonesian government to fit the progress of the times. The K13 2017 Revision is expected to be more capable of producing students with 21 st Century skills. It equips students in developing life skills and careers, learning and innovation, and technology because the concept of 21 st Century learning was characterized by training and developing the 21 st Century skills, which were life and career skill, learning and innovation skills, and also information, media and technology skills [4].

Learning activities based on the K13 2017 Revision should be a focus on enabling students and integrating 4C skills, literacy, HOTS, and character education. Active learning can make a course more enjoyable for both teachers and students, and most importantly, can cause students to think at a higher level [5]. The 4C skill consists of critical thinking and problem solving, communication, creative and innovative, and collaborative. Critical thinking is the basis of the ability to think creatively and reflectively [6]. Literacy has a goal for students to read and make reading as a habit and lifestyle. HOTS is one component of the creative thinking skills and critical thinking [7]. These skills have to include sub-skills such as analysis, synthesis, and evaluation, which are the highest levels in Bloom's cognitive taxonomy [8].

One of the vital factors and generally discussed in relation to the quality of education is the teacher [9]. To enable the curriculum to take effects, teachers as the implementers should show their readiness, willingness, and absolute capability to implement the curriculum by changing their mindset from old and traditional views of learning to modern pedagogic dimension [10]. Teachers' competence is the most important component in the implementation of the K13 [11]. The K13 2017 Revision will not work if teachers as planners and curriculum implementers have low competence. Competence has a positive and significant effect on teacher performance. It means that the higher competence may increase teacher performance [12]. Teachers are key to student learning, and efforts to improve teacher quality [13]. Teacher's understanding of learning affects the way the teacher carries out the lesson. There is clear evidence that ways of understanding learning and teaching mediate teaching practices [14]. However, the teachers' weakness of knowledge and understanding about the pedagogical practices promoted by the new curriculum and the nature of the competencies, together with their narrow interpretation of these, seems to have influenced, if not overtly encouraged, the retention of traditional approaches to pedagogy [15]. Based on this, this study aims to describe the teachers' understanding of the implementation of learning based on the K13 2017 Revision.

\section{RESEARCH METHOD}

This research is a qualitative research. Qualitative research has been described as work done to understand the meaning that is socially constructed by individuals in interaction with their world [16]. Qualitative research methods for the interpretation and analysis of texts already existing or transcribed from talk, observation or video can be used to explore meanings of social and bodily phenomena as how and why human beings act as they do, within their natural context [17]. The strategy used in this research is a case study. A case study through which to examine the roles of gatekeepers, reflexive practice and patience in ethical qualitative research more broadly [18]. To obtain valid data in qualitative research, the research data is tested its validity using triangulation technique. Triangulation refers to using more than one particular approach when doing research in order to get richer, fuller data and/or to help confirm the results of the research [19]. This study uses data triangulation. Data triangulation refers to using multiple data sources in time (gathering data in different times of the day or at different times in a year), space (collecting data on the same phenomenon in multiples sites or test for cross-site consistency) and person (gathering data from different types or level of people e.g. individuals, their family members and clinicians) [20]. Researchers compare and check data interviews that have been done in different time to obtain valid research data.

A qualitative sampling plan describes how many observations, interviews, focus group discussions or cases are needed to ensure that the findings will contribute rich data [21]. Data collection methods most commonly used in qualitative research are individual or group interviews (including focus groups), observation, and document review [22]. The purpose of this study is the description of Mathematics teachers' understanding of learning implementation based on the K13 2017 Revision. The technique of collecting data in this study used interview method. The interview was conducted three times with each research subject. The subjects of this research are two mathematics teachers at SMAN 1 Wuryantoro, Wonogiri Regency. The first subject is a civil servant math teacher, while the second subject is the honorary math teacher. The first subject is called T1 and the second subject becomes T2.

\section{RESULTS AND ANALYSIS}

3.1. $\mathrm{T} 1$

The T1 explains that learning activities on K13 are carried out through the introduction, the contents, and evaluation. Learning activities should integrate 21 st Century skills consisting of 4C, literacy,

The mathematics teachers' understanding of learning process based on ... (Ikhsan Abdul Latif) 
HOTS, and character education. The introduction contains preparing students physically and psychologically, providing motivation to learn, giving apperception, explaining the learning objectives, and conveying the activities that will be done. The contents activities are carried out in accordance with the learning methods that have been planned in the RPP. In this activities also conducted the assessment of learning using assessment for learning. The final activity of learning is the evaluation. In those activities, teachers and students reflect on evaluating the results and activities that have been done. After that, the teacher provides feedback, assigns the task, and informs the lesson plan of the next meeting.

The main teacher's activity of before starting the learning is preparation the students physically and psychologically so that students feel ready and comfortable to follow the learning process. According to T1, the physical and psychological activity of preparing students is done by giving questions about the condition of the students and the class, then inviting students to talk about the problems in life that are not related to the learning materials. Talking with students makes students feel comfortable to learn with the teacher.

After preparing students physically and psychologically, teachers need to provide learning motivation. Motivation constitutes one of the significant backbones of the learning process in student life [23], so teachers need to provide a good learning motivation to make interesting learning process. According to $\mathrm{T} 1$, the activities of providing learning motivation to students is done by conveying the importance of learning linear program materials and Mathematics in life. The Benefit of linear program and Mathematics in life is students can have the ability to think to organize and orderly. Based on the answers, it can be concluded that the learning motivation is appropriate with the Regulation of the Minister of Education and Culture (RMEC) Number 22 of 2016 because the students' learning motivation is given by conveying the benefits and application of teaching materials contextually.

The teacher's activity after giving learning motivation is apperception. Apperception is an introduction delivered by a teacher in learning by linking the previous material with the material to be studied. According to T1, apperception is given to students by asking questions about prerequisite materials in the linear program then conveying the benefits of the linear program in daily life. Prerequisite materials in the linear program are line equation, linear inequality, and linear inequality system. The benefits of a linear program in daily life are determining the most effective way in a company. Determining the most effective way is the work of a thinker. A thinker has a higher salary than a worker or a person who only executes the work. Based on the answers it can be concluded that apperception according to $\mathrm{T} 1$ os appropriate with regulations of the RMEC Number 22 of 2016 because apperception is given by asking questions that relate previous knowledge with the material to be studied.

The next activity is delivery the purpose of learning. According to T1, the learning objectives or basic competencies are presented to students at the beginning of the chapter by displaying the learning objectives or basic competencies in the linear program materials using Microsoft PowerPoint. The learning objectives delivered using Microsoft PowerPoint aims to let students know the expected process and objectives of the basic competence of the linear program, that is Basic Competencies 3.2 and 4.2.

The final of the learning introduction activity is delivery the material coverage and description of the learning activities to be undertaken. According to T1, learning activities are delivered after conveying the learning objectives or basic competencies. Description of learning activities delivered by displaying material using Microsoft PowerPoint and delivering directly to students related to the material or sub-chapters, tasks, and activities to be done on linear program materials.

According to T1, the contents of learning activities are based on the syntax of the planned learning method. The main approach in K13 is scientific or $5 \mathrm{M}$ so that learning activities are prepared by the scientific approach. However, the contents of learning activities that have been conducted by $\mathrm{T} 1$ are consistent with the syntax of the planned learning method only at the beginning of the semester caused by the National Examination and the students' ability to be active in learning. Based on the answer, it can be concluded that the learning activities are appropriate with the RMEC Number 22 of 2016 and The Guidance of Implementation Skills in 21st Century of 2013 Curriculum in Senior High School is the learning activities focus on facilitating students to be active. However, T1's understanding of the K13 2017 Revision approach is less appropriate because a scientific approach is not the only approach can be used in learning.

Based on to T1, assessment of learning achievement is not only done with the assessment of learning but also assessment for learning. The assessment for learning aims to know the weakness of students and teachers in implementing learning. Students are given 2 or 3 items to know the level of understanding of learning materials. Based on the answers it can be concluded that the assessment of learning outcomes according to T1 is appropriate with the Guidelines for Assessment by Educators and High School Education because the assessment used is the assessment for learning or assessment conducted during the learning process and followed efforts to improve the learning process.

According to T1, learning reflection is done by asking students questions about what they have learned, not understood, and already understood. Feedback is the student's answer to reflection questions and 
suggestions on learning activities. Based on the answers it can be concluded that the reflection of learning according to T1 is appropriate with the RMEC Number 22 of 2016 because learning reflection is done by evaluating the series of activities and learning outcomes.

According to T1, follow-up activities are done by assigning tasks to the students to do the questions as homework. After that, the teacher submits the material to be discussed at the next meeting then ask students to find and read the material to be discussed at the next meeting. Based on the answers it can be concluded that follow-up activities according to T1 is appropriate with the RMEC Number 22 of 2016 because follow-up activities are done in the form of assignment, both individual and group tasks.

Adjusting T1, the plan of learning activities for the next meeting is delivered after reflecting on the lesson. In conveying the lesson plans, the teacher presents the material to be discussed at the next meeting.

Learning activities are recommended to integrate 21 st Century skills. According to T1, 4C integration is done by asking students to ask (critical), grouping (collaborative), arguing or communicating the answers in front of the class (communicative), and making uncommon questions (critical and creative). Integration of literacy movement is done by assigning tasks to students to search for material in the library and internet. The LOTS question is conveyed by giving simple questions such as variables, coefficients, while HOTS questions are inserted in the items of test or evaluation. The LOTS query is a simple question or a question of facts, for example, questions about inequality, variables, and coefficients. The character education is done by giving learning motivation and at the end of learning or during evaluation. The integration of character education delivered during the learning motivation is done by conveying the importance of Mathematics and having an orderly and disciplined attitude. At the end of learning or evaluation, character education integration is done by conveying the character in learning Mathematics that is order and discipline. The integration of 21 st Century skills is also appropriated with The Guidance of Implementation Skills in 21st Century of 2013 Curriculum Senior High School, The Concept and Guidelines for Strengthening Character Education, and the School Literacy Movement Guidance at Senior High School.

\section{2. $\mathrm{T} 2$}

T2's explains that the learning activities on K13 are carried out through the introduction, contents, and evaluation activities. Learning activities should integrate on 21 st Century skills consisting of 4C, literacy, HOTS, and character education. The introduction learning activities or opening activities are conducted by preparing students physically and psychologically, providing learning motivation, giving apperception, explaining learning objectives, and conveying the scope of material and description of activities to be performed. The contents activities are carried out based on the learning methods that have been planned in the RPP. The evaluation or closing activities are carried out by reflecting, providing feedback, assigning tasks, and informing the lesson plans of the next meeting.

According to T2, the introduction or opening of lessons is done by preparing students physically and psychologically. Prepare students physically done by asking the condition or news of students, then doing attendance by asking who is absent or not. Preparing students psychologically is done by providing motivation to students.

Motivation is a fundamental element of students' learning; teachers can assist in increasing and developing motivation for optimal achievement in the classroom [24]. According to T2, providing learning motivation to students is done by conveying the benefits of the linear program in daily life. Delivering it program can make students do not think that the material learned in the classroom is separate from their life. Based on these answers can be concluded that the motivation to learn according to T2 is appropriate with the RMEC Number 22 of 2016 because student learning motivation is given by conveying the advantages and application of teaching materials contextually.

According to T2, apperception is given to students by delivering prerequisite material at the previous meeting. The teacher asks questions related to prerequisite or material at the previous meeting on linear program material to know the students' understanding of the linear program material. Based on the answers it can be concluded that apperception according to T2 is appropriate with the RMEC Number 22 of 2016 because apperception is given by asking questions that relate previous knowledge with the material to be studied.

The learning objectives need to be submitted to the students, therefore, students know the expected demands at the end of the lesson. According to T2, the learning objectives and Basic Competence are delivered directly to students at the beginning of the lesson. The learning objectives and Basic Competence are delivered early in the course of the learning with the aim that the students have a picture of the expected demands or expected outcomes in the Basic Competence or linear program material.

According to T2, the scope of the material and the description of the learning activities are delivered early in the lesson by conveying directly to the students about the materials to be discussed at the meeting that day. In addition to delivery the materials, the teacher also conveys the activities to be undertaken. 
T2 explains that T2 seeks to carry out the learning content activity that is appropriate with the syntax of predetermined learning methods. Learning activities are also organized based on student conditions and learning materials. Learning activities are directed at encouraging the students to be active and have a passion for learning. The contents activities based on the student's cognitive stages according to the level of Anderson to be achieved. Based on the answers, it can be concluded that the learning activities according to the T2 is appropriate with the RMEC Number 22 of 2016 and The Guidance of Implementation Skills in 21st Century of 2013 Curriculum in Senior High School because the learning activities focus on facilitating students to be active.

According to T2, learning assessments are derived from daily assessments, tests, and assignments. Each teacher should assess and memorize the abilities and character of each student in each lesson. Based on the answers it can be concluded that the assessment of learning according to T2 is not appropriate with the Guidelines for Assessment by Educators and High School Education because T2 assessment is the only assessment of learning or assessment that conducted after the learning process finished without effort to improve the learning process.

According to T2, learning reflection is done by reminding of the material that has been discussed at the meeting that day. Tha reflection can also be done by giving a test to determine the level of student understanding. The feedback is the process of explaining to students what can be done in learning or outside learning. Based on the answers it can be concluded that the reflection of learning according to $\mathrm{T} 2$ is less appropriate with the RMEC Number 22 of 2016 because the reflection of learning should be done by teachers and students to evaluate the series of activities and learning outcomes or achievement.

According to T2, follow-up activities are done at the end of the learning by assigning tasks to the students with the aim of preparing the students to have activities at home, so that on the learning activities at the next meeting, students are ready and have an idea of the material to be discussed. Many of the tasks assigned to students are given to the students based on their abilities so that the tasks can motivate the students because the students can do the task. The number of items given is one or two questions. Based on the answers it can be concluded that follow-up activities according to T2 is appropriate with the RMEC Number 22 of 2016 because follow-up activities are done in the form of assignment, both individual and group tasks.

According to T2, the plan of learning meeting plan is delivered at the end of the lesson by delivering it directly to the students. The teacher presents the material to be discussed at the next meeting then asks the students to study in advance or prepare the equipment to be used on the next meeting material.

According to $\mathrm{T} 2,4 \mathrm{C}$ integration in learning activities based on learning materials. In the discussion, students are asked actively to find and try the problem solving themselves by way of literacy or browsing. In $4 \mathrm{C}$, teachers provide material accompanied by stimuli related to contextual issues. The literacy movement is integrated into the learning by assigning tasks to the students to find the material to be discussed at the next meeting. HOTS integration is done by guiding the students or giving an illustration of the flow of thinking to solve the problem or understand the concept of the material discussed. The character education is integrated by giving a reprimand to students who behave less well. Character education written in attitude assessment is only a small part that represents student activities.

\section{CONCLUSION}

T2's explains that the learning activities on K13 are carried out through the introduction, contents, and evaluation activities. Learning activities should integrate on 21st Century skills consisting of 4C, literacy, HOTS, and character education. The introduction learning activities or opening activities are conducted by preparing students physically and psychologically, providing learning motivation, giving apperception, explaining learning objectives, and conveying the scope of material and description of activities to be performed. The contents activities are carried out based on the learning methods that have been planned in the RPP. The evaluation or closing activities are carried out by reflecting, providing feedback, assigning tasks, and informing the lesson plans of the next meeting.

According to T2, the introduction or opening of lessons is done by preparing students physically and psychologically. Prepare students physically done by asking the condition or news of students, then doing attendance by asking who is absent or not. Preparing students psychologically is done by providing motivation to students.

Motivation is a fundamental element of students' learning; teachers can assist in increasing and developing motivation for optimal achievement in the classroom [24]. According to T2, providing learning motivation to students is done by conveying the benefits of the linear program in daily life. Delivering it program can make students do not think that the material learned in the classroom is separate from their life. Based on these answers can be concluded that the motivation to learn according to $\mathrm{T} 2$ is appropriate with the 
RMEC Number 22 of 2016 because student learning motivation is given by conveying the advantages and application of teaching materials contextually.

According to $\mathrm{T} 2$, apperception is given to students by delivering prerequisite material at the previous meeting. The teacher asks questions related to prerequisite or material at the previous meeting on linear program material to know the students' understanding of the linear program material. Based on the answers it can be concluded that apperception according to T2 is appropriate with the RMEC Number 22 of 2016 because apperception is given by asking questions that relate previous knowledge with the material to be studied.

The learning objectives need to be submitted to the students, therefore, students know the expected demands at the end of the lesson. According to T2, the learning objectives and Basic Competence are delivered directly to students at the beginning of the lesson. The learning objectives and Basic Competence are delivered early in the course of the learning with the aim that the students have a picture of the expected demands or expected outcomes in the Basic Competence or linear program material.

According to T2, the scope of the material and the description of the learning activities are delivered early in the lesson by conveying directly to the students about the materials to be discussed at the meeting that day. In addition to delivery the materials, the teacher also conveys the activities to be undertaken. T2 explains that T2 seeks to carry out the learning content activity that is appropriate with the syntax of predetermined learning methods. Learning activities are also organized based on student conditions and learning materials. Learning activities are directed at encouraging the students to be active and have the passion for learning. The contents activities based on the student's cognitive stages according to the level of Anderson to be achieved. Based on the answers, it can be concluded that the learning activities according to the T2 is appropriate with the RMEC Number 22 of 2016 and The Guidance of Implementation Skills in 21st Century of 2013 Curriculum in Senior High School because the learning activities focus on facilitating students to be active.

According to T2, learning assessments are derived from daily assessments, tests, and assignments. Each teacher should assess and memorize the abilities and character of each student in each lesson. Based on the answers it can be concluded that the assessment of learning according to T2 is not appropriate with the Guidelines for Assessment by Educators and High School Education because T2 assessment is the only assessment of learning or assessment that conducted after the learning process finished without effort to improve the learning process.

According to T2, learning reflection is done by reminding of the material that has been discussed at the meeting that day. Tha reflection can also be done by giving a test to determine the level of student understanding. The feedback is the process of explaining to students what can be done in learning or outside learning. Based on the answers it can be concluded that the reflection of learning according to T2 is less appropriate with the RMEC Number 22 of 2016 because the reflection of learning should be done by teachers and students to evaluate the series of activities and learning outcomes or achievement.

According to T2, follow-up activities are done at the end of the learning by assigning tasks to the students with the aim of preparing the students to have activities at home, so that on the learning activities at the next meeting, students are ready and have an idea of the material to be discussed. Many of the tasks assigned to students are given to the students based on their abilities so that the tasks can motivate the students because the students can do the task. The number of items given is one or two questions. Based on the answers it can be concluded that follow-up activities according to T2 is appropriate with the RMEC Number 22 of 2016 because follow-up activities are done in the form of assignment, both individual and group tasks.

According to T2, the plan of learning meeting plan is delivered at the end of the lesson by delivering it directly to the students. The teacher presents the material to be discussed at the next meeting then asks the students to study in advance or prepare the equipment to be used on the next meeting material.

According to T2, 4C integration in learning activities based on learning materials. In the discussion, students are asked actively to find and try the problem solving themselves by way of literacy or browsing. In $4 \mathrm{C}$, teachers provide material accompanied by stimuli related to contextual issues. The literacy movement is integrated into the learning by assigning tasks to the students to find the material to be discussed at the next meeting. HOTS integration is done by guiding the students or giving an illustration of the flow of thinking to solve the problem or understand the concept of the material discussed. The character education is integrated by giving a reprimand to students who behave less well. Character education written in attitude assessment is only a small part that represents student activities.

\section{ACKNOWLEDGEMENTS} permission.

We would like to say thank you SMAN 1 Wuryantoro, Wonogiri Regency for giving the research 


\section{REFERENCES}

[1] T. Shilling, "Opportunities and challenges of curriculum mapping implementation in one school setting: considerations for school leaders," Journal of Curriculum and Instruction, vol. 7, pp. 20-37, 2013.

[2] P. C. Rudy, "The perspective of curriculum in indonesia on environmental education," International Journal of Research Studies in Education, vol. 4, pp. 77-83, 2015.

[3] Susilawati, et al, "Project based learning multi life skill for collaborative skills and technological skills of senior high school students," Journal of Physics: Conference Series, vol. 824, 0012015, 2017.

[4] D. H. Putri, et al, "Pre-service physics teachers' perception toward hands-on lab activity and 21 st century skills," Journal of Physics: Conference Series, vol. 895, 012015, 2017.

[5] B. Limbach and W. Waugh, "Developing higher level thinking," Journal of Instructional Pedagogies, vol. 3, 2010. [Online]. Available: AABRI Academic Journals, http://www.aabri.com/manuscripts/09423.pdf.

[6] S. Sukaesih and Sutrisno, "The Effects of Conceptual Understanding Procedures (CUPs) towards critical thinking skills of senior high school students," Journal of Physics: Conference Series, vol. 824, 012070, 2017.

[7] Y. M. Heong, et al, "The level of marzano higher order thinking skills among technical education students," International Journal of Social Science and Humanity, vol. 1, pp. 121-125, 2011.

[8] Y. Abosalem, "Assessment techniques and students' higher-order thinking skills," International Journal of Secondary Education, vol. 4, pp. 1-11, 2016.

[9] Sulisworo, et al, "Identification of teachers' problems in Indonesia on facing global community," International Journal of Research Studies in Education, vol. 6, pp. 81-90, 2016.

[10] D. Ahmad, "Understanding the 2013 curriculum of english teaching through the teachers' and policymakers' perspectives," International Journal of Enhanced Research in Educational Development, vol. 2, pp. 5-15, 2014.

[11] D. Rumahlatu, et al, "An analysis of the readiness and implementation of 2013 curriculum in the west part of Seram District, Maluku Province, Indonesia," International Journal of Environmental \& Science Education, vol. 11, pp. 5662-5675, 2016.

[12] H. M. Arifin, "The influence of competence, motivation, and organisational culture to high school teacher job satisfaction and performance," International Education Studies, vol. 8, pp. 38-45, 2015.

[13] D. L. Ball and F. M. Forzani, "The work of teaching and the challenge for teacher education," Journal of Teacher Education, vol. 60, pp. 497-511, 2009.

[14] J. M. Brownlee, et al, "Understanding learning and teaching in papua new guinea: elementary teacher trainers engaged in cultural authorship in the context of national educational reforms," Australian Journal of Teacher Education, vol. 37, pp. 25-40, 2012.

[15] Sulfasyah, et al, "Indonesian teachers' implementation of new curriculum initiatives in relation to teaching writing in lower primary school," International Journal of Education, vol. 7, pp. 53-72, 2015.

[16] M. Oliver-Hoyo and D. Allen, "The use of triangulation methods in qualitative educational research," Journal of College Science Teaching, vol. 35, pp. 42-47, 2006.

[17] K. Malterud, "Qualitative research: standards, challenges, and guidelines," The Lancet, vol. 358, pp. 483-488, 2011.

[18] H. Kara and L. Pickering, "New directions in qualitative research ethics," vol. 20, pp. 239-241, 2017.

[19] V. Wilson, "Research methods: triangulation," Evidence Based Library and Information Practice,vol. 9, pp. 74-75, 2014

[20] I. Korstjens and A. Moser, "Series: practical guidance to qualitative research. part 4: trustworthiness and publishing," European Journal of General Practice, vol. 24, no. 1, pp. 120-124, 2017.

[21] A. Moser and I. Korstjens, "Series: practical guidance to qualitative research. part 3: sampling, data collection and analysis," European Journal of General Practice, vol. 24, pp. 9-18, 2018.

[22] J. Sargeant, "Qualitative research part ii: Participants, analysis, and quality assurance," Journal of Graduate Medical Education, vol. 4, pp. 1-3, 2012.

[23] G. Dişlen, "The reasons of lack of motivation from the students' and teachers' voices," The Journal of Academic Social Science, vol. 1, pp. 35-45, 2013.

[24] K. M. Valerio, "Intrinsic motivation in the classroom," Journal of Student Engagement: Education Matters, vol. 2, pp. 30-35, 2012. 